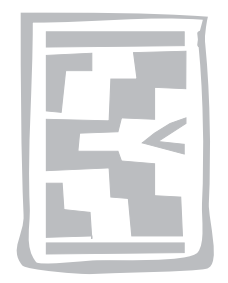

\title{
A retrospective study of the prevalence and seasonal variation of Fasciola gigantica in cattle slaughtered in the major abattoirs of Zimbabwe between 1990 and 1999
}

\author{
D.M. PFUKENYI ${ }^{1 *}$ and S. MUKARATIRWA2
}

\begin{abstract}
PFUKENYI, D.M. \& MUKARATIRWA, S. 2004. A retrospective study of the prevalence and seasonal variation of Fasciola gigantica in cattle slaughtered in the major abattoirs of Zimbabwe between 1990 and 1999. Onderstepoort Journal of Veterinary Research, 71:181-187

A retrospective study covering a period of 10 years (1990-1999) was conducted using post mortem meat inspection records of the Veterinary Department Information Management Unit at Harare to determine the prevalence and seasonal variation of bovine fasciolosis in Zimbabwe. Records of monthly and annual returns from five major abattoirs were examined in regard to total cattle slaughtered and the corresponding number of livers condemned due to Fasciola gigantica infection.

Prevalence of fasciolosis was calculated as the number of cattle found to be infected with F. gigantica, expressed as a percentage of the number of cattle slaughtered. Seasonal variations in the prevalence were examined by pooling respective monthly condemnation data over a 10-year (19901999) period. A total of 2474232 cattle were slaughtered during this period and $917565(37.1 \%)$ of these cattle were infected with F. gigantica. The pattern of distribution of $F$. gigantica was significantly higher in cattle originating from catchment areas of high rainfall than in those of relatively low rainfall, and in those slaughtered during the wet season than those slaughtered during the dry season $(P<0.05)$. Based on the study findings a control programme for the disease in Zimbabwe is suggested.
\end{abstract}

Keywords: Abattoirs, cattle, Fasciola gigantica, prevalence, seasonal variation, Zimbabwe

\section{INTRODUCTION}

Surveys of livestock diseases and condemnation rates at slaughter can give a useful guide to the incidence of the less acute, chronic and mild diseases which occur in production animals in regions served by various abattoirs (Chambers 1987). Therefore, information gathered on animals slaugh-

* Author to whom correspondence is to be directed. E-mail: dmpfukenyi@hotmail.com

1 Central Veterinary Laboratory, Diagnostic and Research Branch, P.O. Box CY551 Causeway, Harare, Zimbabwe

2 University of Zimbabwe, Faculty of Veterinary Science, Department of Paraclinical Veterinary Studies, P.O. Box MP167, Mt Pleasant, Harare, Zimbabwe

Accepted for publication 27 January 2004-Editor tered at an abattoir can be a convenient and inexpensive source of information (Roberts \& Suhardono 1996). The data can be used to determine trends in prevalence and significance of the disease(s) especially where the reporting system is reliable (Roberts \& Suhardono 1996).

In Zimbabwe, both commercial farmers and rural farmers in communal farming areas send their animals for slaughter to various abattoirs in the country. State meat inspectors routinely inspect the slaughtered animals and state public veterinary health officers supervise the inspection of the carcasses. The inspection is done independently of livestock and abattoir owners, and hence they do not have any influence on the inspection. The state keeps all the records. Prevalence of various diseases has 
been reported from data collected at abattoirs in Zimbabwe (Chambers 1987).

From the previous abattoir studies in Zimbabwe, the condemnation rate of livers due to Fasciola gigantica was $46.3 \%$ in 1986, with 527 tons of livers either condemned or trimmed (Chambers 1987) and the loss per head slaughtered amounted to $Z \$ 3.45$. A higher incidence of $F$. gigantica was reported in the higher rainfall areas $(70 \%)$ than the drier areas
(25\%) (Chambers 1987). Between 1988 and the first quarter of 1990 , the condemnation rate ranged from $40.4 \%$ to $43.2 \%$, with losses due to liver condemnation alone exceeding Z\$2 318800 annually (Vassilev \& Jooste 1991).

The objective of this study was to determine the prevalence and seasonal variation of $F$. gigantica in cattle, based on records of the major abattoirs in Zimbabwe during the period of 1990-1999.

TABLE 1 Annual rainfall and temperature for the catchment areas of the selected abattoirs

\begin{tabular}{|l|l|l|l|}
\hline Abattoir & Catchment area (provinces) & Rainfall $(\mathrm{mm})$ and [temperature $\left.\left({ }^{\circ} \mathrm{C}\right)\right]$ ranges & Geographical region \\
\hline Bulawayo & Matebeleland North \& South & $450-600[22-30]$ & Natural regions IV \& V \\
Masvingo & Masvingo \& Midlands & $450-600[22-30]$ & Natural regions IV \& V \\
Kadoma & Midlands \& Mashonaland West & $500-700[18-24]$ & Natural regions III, IV \& V \\
Marondera & Mashonaland East \& Manicaland & $700-1000[18-22]$ & Natural regions I, II \& III \\
Chinhoyi & Mashonaland East \& Central & $700-1000[18-22]$ & Natural regions II \& III \\
\hline
\end{tabular}

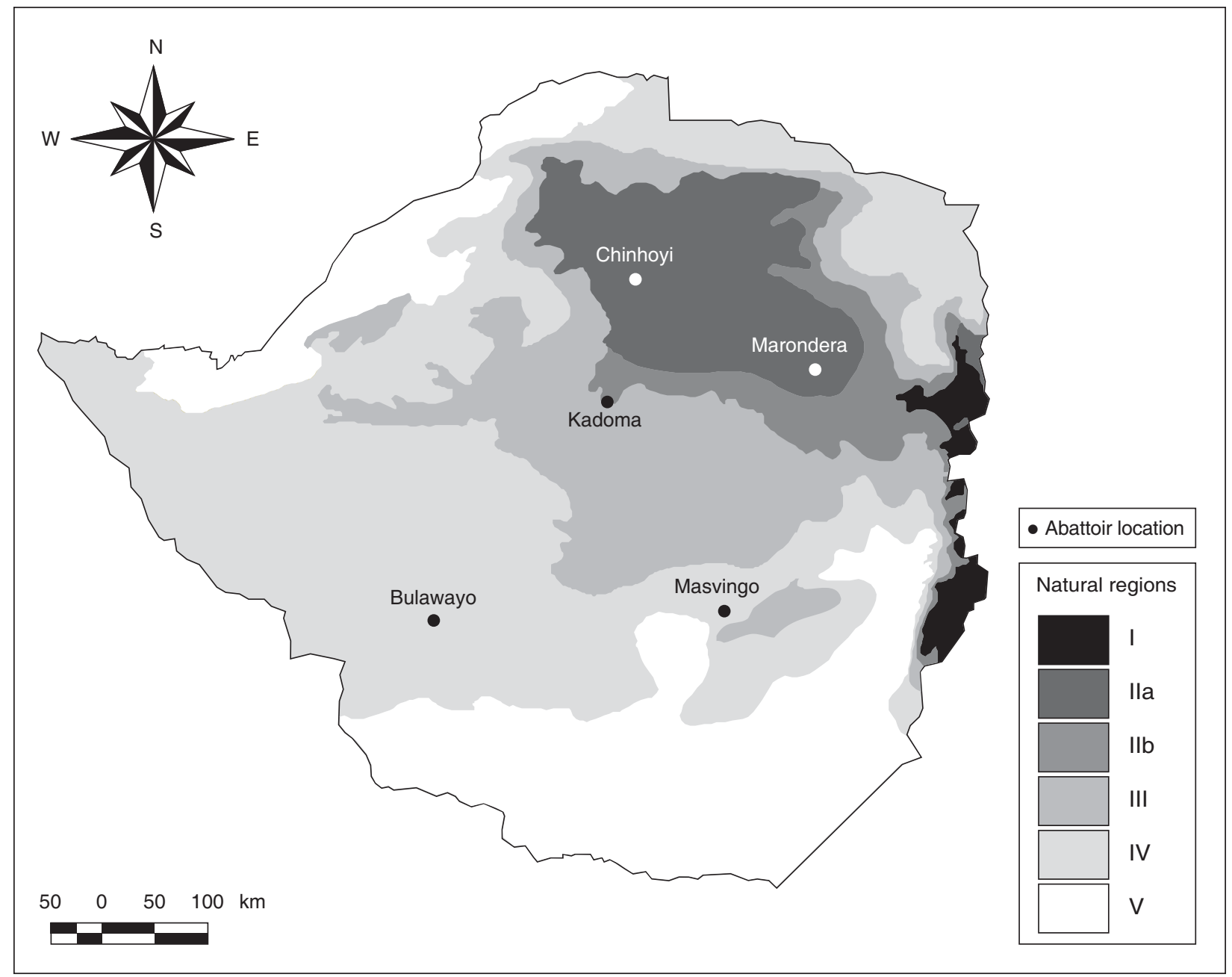

FIG.1 Location of abattoirs in the different natural regions of Zimbabwe 


\section{MATERIALS AND METHODS}

\section{Sampling}

A convenient sample of major abattoirs in Zimbabwe, based on livestock concentration and slaughter capacities, was selected for the study. These abattoirs are owned by the Cold Storage Company (a parastatal company) located in Bulawayo, Chinhoyi, Kadoma, Marondera and Masvingo. The catchment areas of the selected abattoirs cover the main provinces and natural regions of Zimbabwe with varying climatic conditions and they service both the communal and commercial sectors of the country with different cattle management practices (Table 1 and Fig. 1).

Meat inspectors perform the actual meat inspection and veterinary public health officers supervise the inspection of the carcasses. Meat inspection is done in the absence of livestock and abattoir owners and hence they do not have any influence on the inspection.

\section{Data collection and analysis}

Records of meat inspection available at the five abattoirs for the period starting January 1990 to December 1999 were used for this study. Records of monthly and annual returns from the abattoirs were perused in regard to total cattle slaughtered and the corresponding number of livers condemned due to $F$. gigantica infection. The prevalence rate (\%) of F. gigantica was calculated monthly and annually for each abattoir. The overall prevalence for each catchment area was calculated from data collected over a 10-year period (1990-1999). Seasonal variations in the prevalence were examined by pooling respective monthly condemnation data over the 10-year (1990-1999) period.

\section{RESULTS}

The results of the prevalence of $F$. gigantica in cattle according to abattoir and year are shown in Table 2 and the seasonal variations in prevalence are given in Table 3. Between 1990 and 1999, 2474234 cattle were slaughtered in the abattoirs and 917565 livers $(37.1 \%)$ were condemned due to $F$. gigantica infestation. The annual prevalence between 1990 and 1999 varied from approximately $28 \%$ to $42 \%$ and the prevalence was highest in 1991 (42.4\%) and lowest in 1999 (27.6\%). When the prevalence and mean condemnation rates of the disease for the first 5-year period (1990-1994) were compared with those for the succeeding 5-year period (1995-1999), the first period had a significantly higher prevalence and condemnation rates $(P<0.05)$ than the succeeding period.

Marondera (prevalence of $44.9 \%$ ) and Chinhoyi (prevalence of $42.1 \%$ ) abattoirs serving the higher rainfall catchment areas had significantly higher prevalence and mean condemnation rates $(P<$ 0.001 ) than the other abattoirs. When respective monthly figures from 1990-1999 were combined, the highest prevalence was $54.3 \%$ in February and December and the lowest was $17.8 \%$ in September. When the monthly figures were grouped into seasons, the wet season (November to April) had significantly higher prevalence and mean condemnation rates $(P<0.001)$ than the dry season (May to October) (Table 3).

\section{DISCUSSION}

The prevalence of $F$. gigantica as observed in cattle slaughtered at the five main abattoirs in Zimbabwe $(37.1 \%)$ was lower than that reported earlier by Chambers (1987) (46.3\%) and by Vassilev \& Jooste (1991) (40.4-43.2\%). This variation can probably be attributed to the progressive intensification of veterinary and extension services in the country. This has probably made farmers more aware of fasciolosis and hence has accustomed them to apply regular anthelmintic treatment to their cattle. The decline in prevalence is further confirmed by the significantly higher prevalence rate of the disease for the first 5-year period (1990-1994) compared to that of the succeeding 5-year period (1995-1999) observed in the present study.

The prevalence of $F$. gigantica infection observed in cattle slaughtered in the main abattoirs in the country was much higher than that recorded as a result of the coprological examination of cattle (18.5\%) (Pfukenyi 2003). This variation could probably be due to the fact that reports in the abattoir study include livers damaged by immature fluke infection, which cannot be detected through coprological examination.

The pattern of distribution of $F$. gigantica was higher in catchment areas of high rainfall. The highest prevalence of the disease was found at Chinhoyi abattoir in Mashonaland West Province followed by Marondera abattoir in Mashonaland East Province. The present findings confirm earlier reports with regard to the prevalence of the fluke (Needham 1977; Davies 1982; Chambers 1987). In Kenya the 


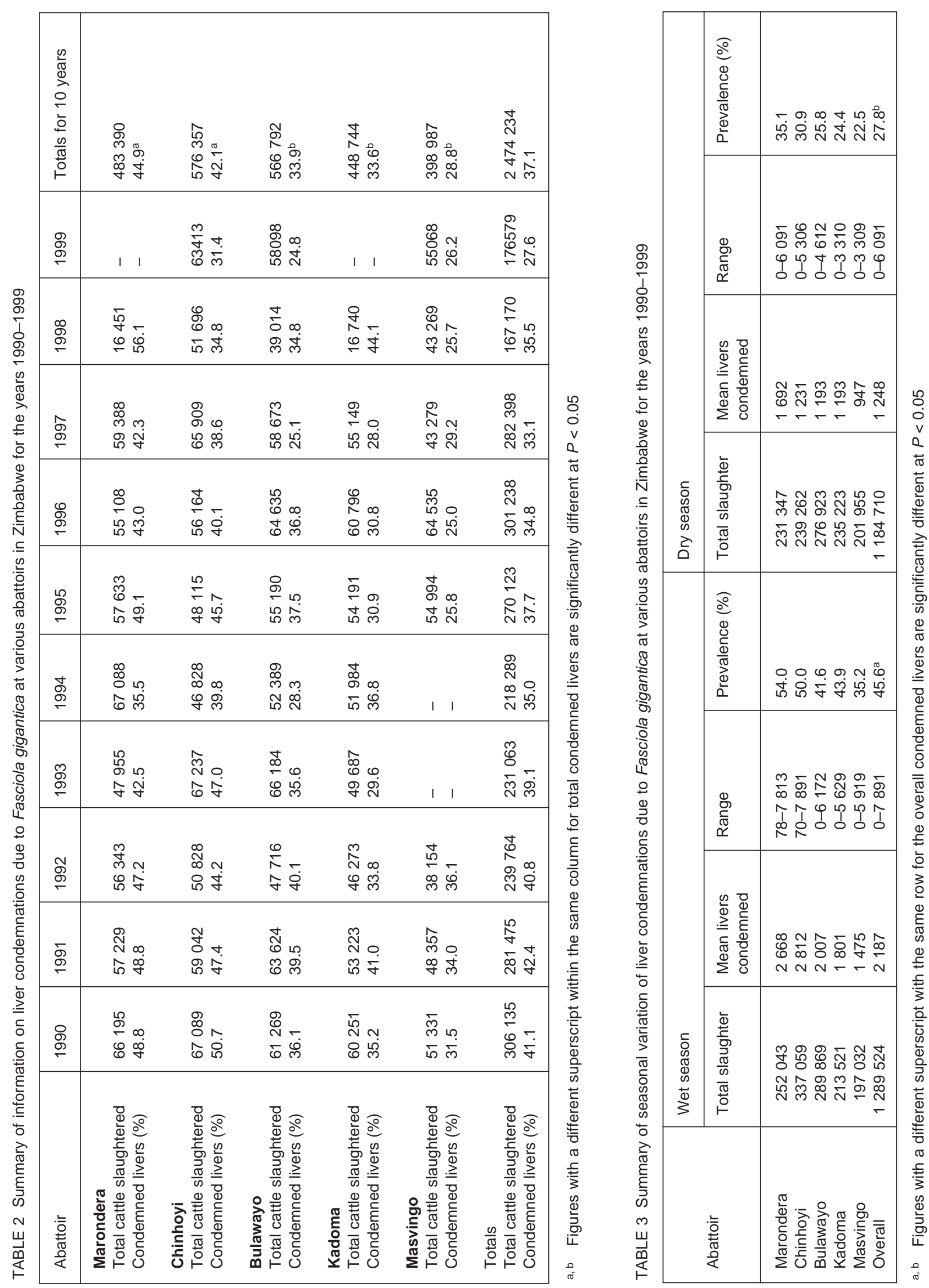


pattern of distribution of fasciolosis also reflected zones of high rainfall (Cheruiyot 1983; Kithuka, Maingi, Njeruh \& Ombui 2002).

The intermediate host of $F$. gigantica in Zimbabwe is the freshwater snail, Lymnaea natalensis (Needham 1977; Davies 1982), which is the most common and widely distributed freshwater snail found in the country and can tolerate a wide range of conditions (Davies 1982; Makura \& Kristensen 1991). It is found in a great variety of habitats including natural water bodies, reservoirs, ornamental ponds and even cattle drinking troughs (Davies 1982). The high prevalence of the disease in cattle slaughtered in Chinhoyi and Marondera abattoirs is probably attributed to the presence of numerous streams and manmade reservoirs in the catchment grazing areas (Davies 1982).

Fasciolosis has been described as enzootic in areas with a mean annual rainfall of over $1016 \mathrm{~mm}$ (Dinnik \& Dinnik 1963, 1964) and L. natalensis is widely distributed in such areas. The presence of the snail hosts is an important factor in the distribution of fasciolosis (Cheruiyot 1983). Lymnaea natalensis was found to be significantly more prevalent in the higher rainfall districts of the country than the drier districts (Pfukenyi 2003). This probably explains the pattern of distribution noted in the present study.

Abattoir studies in Tanzania failed to establish any significant difference in the prevalence rate of fasciolosis between the dry and wet seasons (Hyera 1984); this was attributed possibly to the small sample size of the data collected. In Nigeria, the seasonal prevalence was highest during the periods immediately before and after the onset of rains (Babalola \& Schillhorn van Veen 1976) and immediately after the rainy season (Schillhorn van Veen, Folaranmi, Usman \& Ishaya 1980). The pattern was more a reflection of the marketing policy of the cattle owners than of the epidemiology of fasciolosis. These reports are, however, contrary to our observations in the present study and those from Malawi (Mzembe \& Chaudhry 1981), Sierra Leone (Asanji \& Williams 1984) and Zambia (Pandey \& Ahmadu 1998).

From our observations, the peak condemnation period due to chronic fasciolosis was during the rainy season between December and April. In Malawi, a high percentage of livers condemned due to fasciolosis were between December and July and a high prevalence of the mature parasites in cattle was recorded from December to April (Mzembe \& Chaudhry 1981). A similar pattern was observed in Sierra
Leone (Asanji \& Williams 1984) and Zambia (Pandey \& Ahmadu 1998). Hence, the eggs of mature parasites contaminate the environment during the period December to April. Findings of a significantly higher prevalence of $F$. gigantica during the wet season through coprological examination serve to further confirm the above observations (Vassilev 1994, 1999; Pfukenyi 2003).

In Zimbabwe, the snail population builds up during the beginning of the dry season with a temporary drop during the cold months of June and July and thereafter increases to reach a maximum in October (Shiff 1963; Chingwena 2002; Pfukenyi 2003). Similar observations have been reported in West Africa (McCullough 1965; Schillhorn van Veen 1980), Malawi (Mzembe \& Chaudhry 1979) and Nepal (Morel \& Mahato 1987). It is during the peak in the population that the greatest numbers of snails are liable to infection by $F$. gigantica miracidia and the fluke cycle progresses to the cercarial stage towards the end of winter and beginning of spring (Davies 1982). Investigations of the life cycle of $F$. gigantica in Malawi also indicated that the cercariae are released from July to October and cattle are thus exposed to a high level of infestation from August onwards (Mzembe \& Chaudhry 1979). Therefore, metacercariae ingested by cattle from July onwards leads to a high prevalence of chronic fasciolosis recorded in December to April.

Treatment is still the main method for controlling fasciolosis (Roberts \& Suhardono 1996). Several anthelmintics are effective against cattle liver flukes. However, some anthelmintics are only effective against mature stages (Spithill, Smooker \& Copeman 1999). Triclabendazole is a novel anthelmintic, which has been found to be effective against adult and immature stages of $F$. hepatica (Boray, Crowfoot, Strong, Allison, Schellenbaum, Von Orellin \& Sarasin 1983; Wolff, Eckert, Schneiter \& Lutz 1983) and F. gigantica (Suhardono, Widjajanti \& Carmichael 1991; Waruiru, Weda \& Munyua 1994; Spithill et al. 1999). Clorsulon also has high efficacy against mature and immature F. gigantica (Spithill et al. 1999).

Based on findings from this study anthelmintic treatment should be administered in December/January to control chronic and mature fasciolosis. A second treatment should be given in April/May to reduce pasture contamination and subsequently snail infection, as this is the time the snail population starts to build up. To control acute fasciolosis a third treatment may be given in August. However, this approach would only work if all the communal graz- 
ing animals are treated at the same time with efficient anthelmintics.

Clinical trials carried out in the Netherlands were highly indicative of the presence of triclabendazoleresistant $F$. hepatica in sheep and cattle (Moll, Gaasenbeek, Vellema \& Borgsteede 2000). Gaasenbeek, Moll, Cornelissen, Vellema \& Borgsteede (2001) subsequently reported and confirmed the presence of triclabendazole-resistant $F$. hepatica strains in sheep from a cattle and sheep farm in the Netherlands. Hence indirect measures aimed at reducing the snail population in the environment and reducing chances of the animal's exposure to the snail-infested areas should be pursued.

In Malawi, Mzembe and Chaudhry (1981) recommended the application of molluscicides in June, the time when the snail harbours the parasite and a second application in September in order to kill new generations of infected snails. This proposed intermediate host snail control method could also probably be applicable to Zimbabwe as the population dynamics of the snail hosts are similar. However, molluscicides have mainly been used or recommended for use in dams because the more extensive habitats such as rivers and irrigated rice fields make the cost prohibitive and also because of the adverse effects of some molluscicides on non-targeted animals and plants in the habitat (Spithill et al. 1999). Therefore, attempting to control the snails using molluscicides, especially in the highveld would prove to be impractical due to the widespread distribution of the snail habitats, the high biotic potential of the snails and the recurrent labour and equipment costs.

\section{ACKNOWLEDGEMENTS}

The authors thank the Information Management Unit in the Department of Veterinary Services for allowing access to the meat inspection records and Mr. C. Ncube for the map.

\section{REFERENCES}

ASANJI, M.F. \& WILLIAMS, M.O. 1984. The effect of sex on seasonal variation in single and double infection of cattle in Sierra Leone by Dicrocoelium hospes and Fasciola gigantica. Veterinary Parasitology, 15:247-255.

BABALOLA, D.A. \& SCHILLHORN VAN VEEN, T.W. 1976 Incidence of fasciolosis in cattle slaughtered in Bauchi (Nigeria). Tropical Animal Health and Production, 8:243-247.

BORAY, J.C., CROWFOOT, P.D., STRONG, M.B, ALLISON, J.R., SCHELLENBAUM, M., VON ORELLIN, M. \& SARASIN, G. 1983. Treatment of immature and mature Fasciola hepatica infections in sheep with triclabendazole. The Veterinary Record, 113:315-317.

CHAMBERS, P.G. 1987. Carcass and offal condemnations at meat inspection in Zimbabwe. Zimbabwe Veterinary Journal, 18:11-18.

CHERUIYOT, H.K. 1983. Bovine helminths parasites of economic importance- Abattoir survey in Kenya 1976-1980. Bulletin of Animal Health and Production in Africa, 31:367375.

CHINGWENA, G. 2002. Taxonomy, ecology and larval trematode infections of freshwater snails in the highveld and lowveld areas of Zimbabwe with emphasis on amphistome and schistosome intermediate hosts. D.Phil. thesis, University of Zimbabwe.

DAVIES, R. 1982. Fascioliasis in Zimbabwe. The Zimbabwe Science News, 16:182-185.

DINNIK, J.A. \& DINNIK, N.N. 1963. Effect of the seasonal variations of temperature on the development of Fasciola gigantica in the snail host in the Kenya Highlands. Bulletin of Epizootic Diseases of Africa, 11:197-207.

DINNIK, J.A. \& DINNIK, N.N. 1964. The influence of temperature on the succession of redial and cercarial generations of Fasciola gigantica in a snail host. Parasitology, 54:59-65.

GAASENBEEK, C.P.H., MOLL, L., CORNELISSEN, J.B.W.J., VELLEMA, P. \& BORGSTEEDE, F.H.M. 2001. An experimental study on triclabendazole resistance of Fasciola hepatica in sheep. Veterinary Parasitology, 95:37-43.

HYERA, J.M.K. 1984. Prevalence, seasonal variation and economic significance of fasciolosis in cattle as observed at Iringa abattoir between 1976 and 1980. Bulletin of Animal Health and Production in Africa, 32:356-359.

KITHUKA, J.M., MAINGI, N., NJERUH, F.M. \& OMBUI, J.N. 2002. The prevalence and economic importance of bovine fasciolosis in Kenya-an analysis of abattoir data. Onderstepoort Journal of Veterinary Research, 69:255-262.

MAKURA, O. \& KRISTENSEN, T.K. 1991. National freshwater survey of Zimbabwe. Proceedings of the Tenth International Malacology Congress (Tubingen): 227-232.

McCULLOUGH, F.S. 1965. Lymnaea natalensis and fascioliasis in Ghana. Annals of Tropical Medicine and Parasitology, 59:320-326.

MOLL, L., GAASENBEEK, C.P.H., VELLEMA, P. \& BORGSTEEDE, F.H.M. 2000. Resistance of Fasciola hepatica against triclabendazole in cattle and sheep in The Netherlands. Veterinary Parasitology, 91:153-158.

MOREL, A.M. \& MAHATO, S.N. 1987. Epidemiology of fasciolosis in the Koshi hills of Nepal. Tropical Animal Health and Production, 19:33-38.

MZEMBE, S.A.T. \& CHAUDHRY, M.A. 1979. The Epidemiology of Fasciolosis in Malawi. Part 1. The epidemiology in the intermediate host. Tropical Animal Health and Production, 11:246-250.

MZEMBE, S.A.T. \& CHAUDHRY, M.A. 1981. The Epidemiology of Fasciolosis in Malawi. Part 11. Epidemiology in the definitive host. Tropical Animal and Health Production, 13:27-33.

NEEDHAM, A.J.E. 1977. Observations on the economics of treatment of Fasciola gigantica infestation in cattle in Rhodesia. Rhodesia Veterinary Journal, 8:14-20.

PANDEY, G.S. \& AHMADU, B. 1998. Prevalence, seasonal variation and economic importance of bovine fasciolosis in Western Province of Zambia. Zimbabwe Veterinary Journal, 29:63-69.

PFUKENYI, D.M. 2003. Epidemiology of amphistomes, Fasciola gigantica and Schistosoma mattheei in cattle in the highveld 
and lowveld communal grazing areas of Zimbabwe. D.Phil. thesis, University of Zimbabwe.

ROBERTS, J.A. \& SUHARDONO, S. 1996. Approaches to the control of fasciolosis in ruminants. International Journal for Parasitology, 26:971-981.

SCHILLHORN VAN VEEN, T.W. 1980. Dynamics of Lymnaea natalensis population in the Zaria area (Nigeria) and the relation to Fasciola gigantica infections. Acta Tropica, 37: 183- 194.

SCHILLHORN VAN VEEN, T.W., FOLARANMI, D.O.B., US MAN, S. \& ISHAYA, T. 1980. Incidence of liver fluke infections (Fasciola gigantica and Dicrocoelium hospes) in ruminants in northern Nigeria. Tropical Animal Health and Production, 12:97-104.

SHIFF, C.J. 1963. The influence of temperature in the ecology of the intermediate host snails of Schistosoma and Fasciola (Trematoda) in Southern Rhodesia. Ph.D. thesis, Rhodes University.

SPITHILL, T.W., SMOOKER, P.M. \& COPEMAN, D.B. 1999. Fasciola gigantica: Epidemiology, Control, Immunology and Molecular Biology, in Fasciolosis, edited by J.P. Dalton. Dublin City University: CABI Publishing.
SUHARDONO, S., WIDJAJANTI, P.S. \& CARMICHAEL, I.H. 1991. Control of Fasciola gigantica with triclabendazole in Indonesian cattle. Tropical Animal Health and Production, 23:217-220.

VASSILEV, G. \& JOOSTE, R. 1991. Production losses and control of fasciolosis in cattle in Zimbabwe. Zimbabwe Veterinary Journal, 22:45-51.

VASSILEV, G.D. 1994. Prevalence and seasonality of internal parasite infections detectable by faecal examination of cattle in Chiweshe communal farming area of Zimbabwe. Zimbabwe Veterinary Journal, 25:41-63

VASSILEV, G.D. 1999. Prevalence of internal parasite infections of cattle in the communal farming areas of Mashonaland East Province, Zimbabwe. Zimbabwe Veterinary Journal, 30:1-17.

WOLFF, K., ECKERT, J., SCHNEITER, G. \& LUTZ, H. 1983. Efficacy of triclabendazole against Fasciola hepatica in sheep and goats. Veterinary Parasitology, 13:145-150.

WARUIRU, R.M., WEDA, E.H. \& MUNYUA, W.K. 1994. The efficacy of triclabendazole and oxyclozanide against Fasciola gigantica in naturally infected dairy cattle in Kenya. Bulletin of Animal Health and Production in Africa, 42:205-209. 